\title{
Colitic Cancer Develops Through Mutational Alteration Distinct from that in Sporadic Colorectal Cancer: A Comparative Analysis of Mutational Rates at Each Step
}

\author{
TOSHIAKI TANAKA ${ }^{1 *}$, TAKASHI KOBUNAI ${ }^{2 *}$, YOKO YAMAMOTO ${ }^{1}$, SHIGENOBU EMOTO $^{1}$, \\ KOJI MURONO ${ }^{1}$, MANABU KANEKO ${ }^{1}$, KAZUHITO SASAKI $^{1}$, KENSUKE OTANI ${ }^{1}$, TAKESHI NISHIKAWA ${ }^{1}$, \\ KAZUSHIGE KAWAI ${ }^{1}$, KEISUKE HATA ${ }^{1}$, HIROAKI NOZAWA ${ }^{1}$ and TOSHIAKI WATANABE ${ }^{1}$ \\ ${ }^{1}$ Department of Surgical Oncology, the University of Tokyo, Tokyo, Japan; \\ ${ }^{2}$ Translational Research Laboratory, Taiho Pharmaceutical Co., Ltd., Tokyo, Japan
}

\begin{abstract}
Background: Patients with ulcerative colitis (UC) are at risk of UC-associated colorectal cancer (CRC); however, little is known about genetic alterations occurring during UC carcinogenesis. We examined mutational changes in patients with colitic cancer and the features that differed between the carcinogenesis of UC and sporadic CRC. Material and Methods: Specimens were obtained from the non-neoplastic mucosa and cancer cells of 12 patients with colitic cancer. The mutational rate of oncogenes in colitic cancer was analyzed and compared to that of oncogenes in sporadic CRC. Results: We observed a lower mutation rate in adenomatous polyposis coli (APC) $(16.7 \%(2 / 12) v s$. $75.9 \%(161 / 212)$, respectively, $p=0.0001)$ and KRAS $(16.7 \%(2 / 12)$ vs. $42 \%$ (89/212), respectively, $p=0.04)$ in colitic cancer than in sporadic CRC. With respect to cadherin $1(C D H 1)$ and fibroblast growth factor receptor 2 (FGFR2), the mutational rates for non-neoplastic colorectal mucosa were similar to those in sporadic CRC. Conclusion: We demonstrated that mutational rates for APC and KRAS differ between colitic cancer and sporadic CRC. Furthermore, we revealed that $\mathrm{CDH} 1$ and $F G F R 2$ become mutated at an earlier stage in colitic carcinogenesis than in sporadic CRC.
\end{abstract}

Colorectal carcinogenesis is considered to develop through multistep genetic or epigenetic alteration along with the

This article is freely accessible online.

*These Authors contributed equally to this study.

Correspondence to: Toshiaki Tanaka MD, Ph.D., Department of Surgical Oncology, the University of Tokyo, Tokyo, Japan. E-mail: toshi-t@venus.dti.ne.jp

Key Words: Ulcerative colitis, carcinogenesis, CDH1, FGFR2. pathological change called the adenoma-carcinoma sequence (1-5). Further accumulation of genetic changes confers invasiveness or metastatic potential on the tumor $(6,7)$, and to date, several indicators have been identified to predict outcomes $(7,8)$. In contrast, colitic cancer, which develops through inflammation-prone carcinogenesis in patients with ulcerative colitis (UC), has a somewhat different etiology (9). $\mathrm{UC}$ is characterized by chronic inflammation of the colonic mucosa, and the underlying causes of inflammation are the disturbance or disorganization of the epithelial barrier, alteration of colonic microflora, and abnormal immune response caused by the dysregulation of the mucosal immune system (10). During the progression of colitis, genetic alterations associated with mucosal permeability $[e . g$. those in extracellular matrix protein $1(E C M 1)$, cadherin $1(C D H 1)$, and hepatocyte nuclear factor 4 alpha $(H N F 4 A)$ ] have been observed and considered to confer the risk of severe UC (11, 12). The pathogenesis of colitic cancer originates from longstanding and severe bowel inflammation and differs from that of sporadic CRC in several aspects. For instance, colitic cancer often occurs multifocally and is widespread; therefore, performing total coloproctectomy is recommended if any dysplastic or cancerous lesions are identified in patients with UC. Moreover, the behavior and morphology of colitic cancer differ from those of sporadic CRC in that colitic cancer often invades to deeper layers of the bowel wall at an earlier stage of progression; this feature makes it difficult to identify dysplastic lesions when the tumor elevation and size is not large. These distinctive characteristics of colitic cancer are likely to be caused by its genetic etiology, which is different from that of sporadic cancer. However, to date, little information is available in this regard.

In this study, we compared the mutation of oncogenes in colitic cancer to those in sporadic cancer. In addition, we examined the non-neoplastic mucosa of patients with colitic cancer, so as to identify the step in UC carcinogenesis in 
which mutation occurs. To our knowledge, this is the first study examining the mutational difference between colitic cancer and sporadic CRC together with non-neoplastic mucosa in UC.

\section{Materials and Methods}

Study design and patient selection. This was a retrospective study conducted at a single institute. Patients with UC were recruited from the Department of Surgical Oncology, University of Tokyo Hospital, Tokyo, Japan. This study was approved by the Ethics Committee of University of Tokyo Hospital (approval number: G3551), and patients gave their written informed consent for the storage and the use of their specimens in advance. Twelve patients with UC whose resected specimens were stored at our institute were enrolled in this study.

Sample collection and nucleic acid isolation. Specimens were obtained from carcinoma and non-neoplastic colorectal mucosa from all the patients with colitic cancer for DNA analysis. Samples were obtained either from surgically resected specimens or during surveillance colonoscopy. The samples were snap-frozen in liquid nitrogen immediately after resection and were stored at $-80^{\circ} \mathrm{C}$ until DNA extraction. Nuclear DNA was extracted from epithelial cells and carcinoma cells using a DNAeasy kit (Qiagen, Tokyo, Japan). The normal mucosa samples were microscopically verified by experienced pathologists as not containing neoplastic lesions. For the samples of carcinoma, the pathologists verified that the samples contained viable carcinoma cells without necrotic tissue. The concentrations of extracted double-stranded DNA were measured using a Qubit 2.0 fluorometer and Qubit proprietary reagents and dyes (Life Technologies, Grand Island, NY, USA).

Mutational analysis by next generation sequencing (NGS). Targeted resequencing was performed using the TruSeq Amplicon Cancer Panel with the MiSeq ${ }^{\circledR}$ sequencing platform according to the manufacturer's instructions (Illumina, San Diego, CA, USA). The panel contains primer sets to generate 212 amplicons from 48 cancerrelated genes, which include ABL proto-oncogene 1 ( $A B L 1)$, AKT serine/threonine kinase 1 ( $A K T 1)$, ALK receptor tyrosine kinase $(A L K)$, adenomatous polyposis coli $(A P C)$, ATM serine/threonine kinase $(A T M), \mathrm{B}-\mathrm{Raf}$ proto-oncogene, serine/threonine kinase $(B R A F)$, cadherin $1(C D H 1)$, cyclin-dependent kinase inhibitor $2 \mathrm{~A}$ $(C D K N 2 A)$, colony stimulating factor 1 receptor $(C S F 1 R)$, betacatenin $1(C T N N B 1)$, epidermal growth factor receptor $(E G F R)$, Erb$\mathrm{B} 2$ receptor tyrosine kinase $2(E R B B 2)$, Erb-B2 receptor tyrosine kinase 4 (ERBB4), F-Box and WD repeat domain containing 7 (FBXW7), fibroblast growth factor receptor 1 (FGFR1), FGFR2, FGFR3, Fms-related tyrosine kinase 3 (FLT3), G protein subunit alpha 11 (GNA11), GNAQ, GNAS, hepatocyte nuclear factor 1-alpha (HNF1A), HRas proto-oncogene, GTPase (HRAS), cytosolic isocitrate dehydrogenase $1(I D H 1)$, Janus kinase 2 (JAK2), JAK3, kinase insert domain receptor $(K D R)$, KIT proto-oncogene receptor tyrosine kinase (KIT), Kirsten RAS proto-oncogene (KRAS), MET proto-oncogene (MET), MutL homolog 1 (MLH1), MPL protooncogene (MPL), NOTCH1, nucleophosmin (NPM1), NRAS protooncogene $(N R A S)$, platelet-derived growth factor receptor alpha (PDGFRA), phosphatidylinositol-4,5-bisphosphate 3-kinase catalytic subunit alpha $(P I K 3 C A)$, phosphatase and tensin homolog $(P T E N)$, protein tyrosine phosphatase, non-receptor type 11 (PTPN11), RB transcriptional corepressor $1(R B 1)$, Ret proto-oncogene $(R E T)$, SMAD family member 4 (SMAD4), SWI/SNF-related matrixassociated actin-dependent regulator of chromatin, subfamily B, member 1 (SMARCB1), Smoothened, frizzled class receptor (SMO), SRC proto-oncogene (SRC), serine/threonine kinase 11 (STK11), tumor protein P53 (TP53), and Von Hippel-Lindau tumor suppressor $(V H L)$. Multiplexed libraries were subjected to cluster generation using a MiSeq Reagent Kit v2 (300 cycles) in an MiSeq desktop sequencing systems (Illumina). MiSeq Reporter software performs secondary analysis on the base calls and Phred-like quality score (Qscore) generated by Real Time Analysis software during the sequencing run. Alignment of paired-end raw reads to the amplicon sequences specified in the manifest file (Homo sapiens, hg19, build 37.2) was performed with a banded Smith-Waterman alignment algorithm. The Somatic Variant Caller algorithm v3.5.2.1 was used for identification of variants from aligned reads. Variants were annotated by Variant Studio ver.1.0.0 on BaseSpace Cloud (Illumina). Each single variant reported in the VCF output file was evaluated for coverage and the Qscore and visualized via AVADIS NGS software ver.2.7 (Strand Genomics Inc., San Francisco, CA, USA). We applied a minimum threshold in Qscore of 30 (base call accuracy of $99.9 \%$ ) and a sequencing depth $>100$ on reads, which was considered suitable for further analysis. Variants with a global minor allelic frequency of greater than $1.0 \%$ were removed because they were considered common single nucleotide polymorphisms. Copy number variations were also estimated in samples using normal reference coverage profiles via AVADIS NGS.

Statistical analysis and software. The mutational rates of genes in colitic cancer observed in our specimens were compared with the existing data of The Cancer Genome Atlas (TCGA) obtained from Bio-portal (13). The difference between these two categorized values was assessed by Fisher's exact or chi-square test. $p$-Values of less than 0.05 were considered to indicate statistical significance. All statistical analyses were carried out using JMP v9.02 (SAS Institute, Cary, NC, USA).

\section{Results}

Table I shows the gene mutations that were found in the 12 patients with UC. $A P C$, known to occur at an early stage of sporadic colorectal carcinogenesis, was mutated in only two (16.7\%) out of 12 patients with UC. Other key molecules of carcinogenesis showed moderate-to-high mutational rates in colitic cancer (KRAS: $16.7 \%$, TP53: $58.3 \%$, and FBXW7: $25.3 \%$ ). These mutational changes had already occurred in nonneoplastic mucosa - albeit at lower mutational rates. $C H D 1$, known to modulate cell adhesion, mutated in one $(8.3 \%)$ case of non-neoplastic mucosa. FGFR2, a molecule involved in the development of fibroblasts, healing and degeneration, was mutated in three $(25.0 \%)$ case of non-dysplastic UC mucosa. Neither CHD1 nor FGFR2 accumulated further mutations in colitic cancer cells. No mutation was observed in other molecules in non-neoplastic mucosa.

Next, we compared our results to the mutational rate of sporadic CRC obtained from Bioportal (TCGA Nature, 2012). Table II shows the categorized comparison and the result of 
Table I. Genes found to be mutated $(X)$ in non-neoplastic mucosa $(M)$ and carcinoma epithelium $(T)$ of patients with colitic cancer.

\begin{tabular}{|c|c|c|c|c|c|c|c|c|c|c|c|c|c|c|c|c|c|c|c|c|c|c|c|c|c|c|}
\hline \multicolumn{27}{|c|}{ Patient } \\
\hline & \multicolumn{2}{|c|}{ P01 } & \multicolumn{2}{|c|}{ P02 } & \multicolumn{2}{|c|}{ P03 } & \multicolumn{2}{|c|}{ P04 } & \multicolumn{2}{|c|}{ P05 } & \multicolumn{2}{|c|}{ P06 } & \multicolumn{2}{|c|}{ P07 } & \multicolumn{2}{|c|}{ P08 } & \multicolumn{2}{|c|}{ P09 } & \multicolumn{2}{|c|}{ P10 } & \multicolumn{2}{|c|}{ P11 } & \multicolumn{2}{|c|}{$\mathrm{P} 12$} & \multicolumn{2}{|c|}{$\begin{array}{c}\text { Frequency } \\
(\%)\end{array}$} \\
\hline Gene & $\mathrm{M}$ & $\mathrm{T}$ & $\mathrm{M}$ & $\mathrm{T}$ & M & $\mathrm{T}$ & $\mathrm{M}$ & $\mathrm{T}$ & $\mathrm{M}$ & $\mathrm{T}$ & $\mathrm{M}$ & $\mathrm{T}$ & $\mathrm{M}$ & $\mathrm{T}$ & $\mathrm{M}$ & $\mathrm{T}$ & M & $\mathrm{T}$ & $\mathrm{M}$ & $\mathrm{T}$ & M & $\mathrm{T}$ & $\mathrm{M}$ & $\mathrm{T}$ & $\mathrm{M}$ & $\mathrm{T}$ \\
\hline$A P C$ & & & & & & & & & & & & & & $X$ & & & & & & & $X$ & $X$ & & & 8.3 & 16.7 \\
\hline $\mathrm{CDH} 1$ & & & & & & & & & & & & & & & & & & & $X$ & $X$ & & & & & 8.3 & 8.3 \\
\hline ERBB 4 & & & & & & & & & & & & & & & & & & & & & & $X$ & & & 0.0 & 8.3 \\
\hline$F B X W 7$ & & & & & & & & & & & & $X$ & & & & & $X$ & $X$ & & & & & & $X$ & 8.3 & 25.0 \\
\hline$F G F R 2$ & & & & & & & & & & & $\mathrm{X}$ & $\mathrm{X}$ & & & & $\mathrm{X}$ & $X$ & $X$ & & & $\mathrm{X}$ & & & & 25.0 & 25.0 \\
\hline$K R A S$ & & $X$ & & & & & & & & & & $\mathrm{X}$ & & & & & $\mathrm{X}$ & & & & & & & & 8.3 & 16.7 \\
\hline PIK $3 C A$ & & & & & & & & & & & & & & & & & & & & $X$ & & & & & 0.0 & 8.3 \\
\hline$S M A D 4$ & & & & & & & & & & & & & & & & $X$ & & & & & & $X$ & & & 0.0 & 16.7 \\
\hline TP53 & & & & $X$ & & & & $\mathrm{X}$ & & & & $X$ & & $\mathrm{X}$ & $\mathrm{X}$ & $X$ & & $X$ & & $X$ & & & $\mathrm{X}$ & & 16.7 & 58.3 \\
\hline
\end{tabular}

Fisher's test of oncogenes. The mutational rates for $C D K N 2 A$ and NOTCH1 were not registered in Bioportal (TCGA Nature, 2012) and were, therefore, excluded from further analysis.

The mutational rate of $A P C$ was lower in colitic than sporadic CRC (16.7\% vs. $75.9 \%$, respectively, $p=0.0001)$. We also observed a lower mutational rate of KRAS in colitic than in sporadic CRC (67\% vs. 42\%, respectively, $p=0.04)$. Regarding FGFR2, the mutational rate was higher in colitic than in sporadic CRC $(25 \%$ vs. $1.5 \%, p=0.0025)$. No statistical difference was found in mutational rates for $\mathrm{CDH} 1$ or other genes.

\section{Discussion}

Patients with longstanding UC are at an increased risk of developing colitic cancer. Several reports, including metaanalyses, described the estimated risk of colitic cancer at 10 , 20 , and 30 years as $0.5-2 \%, 1.1-8 \%$, and $18 \%$, respectively, and the risk for dysplasia at these time points was estimated as $3.1 \%, 10 \%$, and $15.6 \%$, respectively (14-16). Colitic cancer develops in a widespread distribution among sites of inflammation, and this feature makes early detection difficult. In order to detect dysplastic lesions, we performed non-target biopsy during annual colonoscopy, taking a biopsied specimen every $10 \mathrm{~cm}$ all around the colon, and an additional specimen was taken if it presented as an elevation or had an abnormal color (16). We also introduced a dye-spraying method along with magnifying colonoscopy for the purpose of improving the detection rate of dysplasia $(17,18)$. Together with these efforts, the introduction of biomarkers for dysplasia or colitic cancer is expected to facilitate earlier detection. For this purpose, we examined the genetic alterations specific to colitic cancer.
In this study, we found a much lower mutational rate of $K R A S$ than that of sporadic cancer, compatible to a previous report (19). KRAS plays a key role in intracellular signal transduction pathways, and its mutation is observed in approximately $40 \%$ of CRC. The rate of mutation in sporadic CRC increases with tumor progression, and mutations affect survivals (20). The reason for the lower mutational rate in colitic cancer is unclear; however, we consider one reason to be that most of the colitic cancer cases in our study were detected through annual colonoscopy, which led to early-stage detection. Future studies conducting further analysis to determine whether the mutational rate changes as clinical stage progresses in colitic cancer are warranted.

Another representative genetic alteration observed in sporadic CRC is of $A P C$, which we found to have a lower mutational rate in colitic cancer, in line with a previous report (13). Rapozo et al. reported that $A P C$ mutation did not occur in the mucosa of patients with UC (21), and a study by Odze et al. showed the rates of allelic loss of $A P C$ were similar among precancerous lesions in both normal adenoma $(33 \%)$ and UC-associated dysplasia-associated lesions or masses (29-43\%) (22). In our study, the rate of $A P C$ mutation was much higher in sporadic CRC than in colitic cancer $(73 \%$ vs. $17 \%$, respectively). These results suggest that $A P C$ mutation is involved while adenoma progresses to sporadic cancer, whereas this alteration does not exist in UC carcinogenesis.

We also found a higher mutational rate of FGFR2 in colitic cancer than in sporadic CRC. This alteration had already been observed in the non-neoplastic mucosa of colitis. Basic fibroblast growth factor (bFGF) is reported to be a key molecule in healing and degeneration (23). Higher serum levels of bFGF have been observed in various collagen-related diseases (24), and this is considered to be induced by immune dysfunction. 
Table II. Comparison of mutational rates in colitic cancer epithelium (UC-Ca) determined in this study by next-generation sequencing and in sporadic CRC data obtained from Bioportal (TCGA Nature 2012).

\begin{tabular}{|c|c|c|c|c|c|}
\hline Gene & Encoded protein & Mutation & $\mathrm{UC}-\mathrm{Ca}, \mathrm{n}$ & TCGA nature 2012, $\mathrm{n}$ & $p$-Value* \\
\hline \multirow[t]{2}{*}{$A B L 1$} & ABL proto-Oncogene 1 & + & 0 & 1 & n.s. \\
\hline & & - & 12 & 37 & \\
\hline \multirow[t]{2}{*}{$A K T 1$} & ALT serine/threonine kinase 1 & + & 0 & 1 & n.s. \\
\hline & & - & 12 & 37 & \\
\hline \multirow[t]{2}{*}{$A L K$} & ALK receptor tyrosine kinase & + & 0 & 4 & n.s. \\
\hline & & - & 12 & 34 & \\
\hline \multirow[t]{2}{*}{$A P C$} & Adenomatous polyposis coli & + & 2 & 161 & 0.0001 \\
\hline & & - & 10 & 51 & \\
\hline \multirow[t]{2}{*}{$A T M$} & ATM serine threonine kinase & + & 0 & 5 & n.s. \\
\hline & & - & 12 & 33 & \\
\hline \multirow[t]{2}{*}{$B R A F$} & B-Raf proto-oncogene, serine/threonine kinase & + & 0 & 21 & n.s. \\
\hline & & - & 12 & 191 & \\
\hline \multirow[t]{2}{*}{$\mathrm{CDH1}$} & Cadherin 1 & + & 1 & 5 & n.s. \\
\hline & & - & 11 & 207 & \\
\hline \multirow[t]{2}{*}{$C S F 1 R$} & Colony-stimulating factor 1 receptor & + & 0 & 1 & n.s. \\
\hline & & - & 12 & 37 & \\
\hline \multirow[t]{2}{*}{$C T N N B 1$} & Beta-Catenin 1 & + & 0 & 3 & n.s. \\
\hline & & - & 12 & 35 & \\
\hline \multirow[t]{2}{*}{$E G F R$} & Epidermal growth factor receptor & + & 0 & 3 & n.s. \\
\hline & & - & 12 & 35 & \\
\hline \multirow[t]{2}{*}{$E R B B 2$} & Erb-B2 receptor tyrosine kinase 2 & + & 0 & 3 & n.s. \\
\hline & & - & 12 & 35 & \\
\hline \multirow[t]{2}{*}{ ERBB 4} & Erb-B2 receptor tyrosine kinase 4 & + & 1 & 17 & n.s. \\
\hline & & - & 11 & 195 & \\
\hline \multirow[t]{2}{*}{$F B X W 7$} & F-BOX and WD repeated domain containing 7 & + & 3 & 34 & n.s. \\
\hline & & - & 9 & 178 & \\
\hline \multirow[t]{2}{*}{ FGFR1 } & Fibroblast growth factor receptor 1 & + & 0 & 1 & n.s. \\
\hline & & - & 12 & 56 & \\
\hline \multirow[t]{2}{*}{$F G F R 2$} & Fibroblast growth factor receptor 2 & + & 3 & 3 & 0.0025 \\
\hline & & - & 9 & 197 & \\
\hline \multirow[t]{2}{*}{$F G F R 3$} & Fibroblast growth factor receptor 3 & + & 0 & 1 & n.s. \\
\hline & & - & 12 & 37 & \\
\hline \multirow[t]{2}{*}{ FLT3 } & Fms related thyrosine kinase 3 & + & 0 & 4 & n.s. \\
\hline & & - & 12 & 208 & \\
\hline GNA11 & G Protein subunit alpha 11 & + & 0 & 1 & n.s. \\
\hline & & - & 12 & 211 & \\
\hline$G N A Q$ & G Protein subunit alpha $\mathrm{Q}$ & + & 0 & 1 & n.s. \\
\hline & & - & 12 & 56 & \\
\hline GNAS & G Protein subunit alpha $S$ & + & 0 & 6 & n.s. \\
\hline & & - & 12 & 122 & \\
\hline$H N F 1 A$ & HNF1 Homobox A & + & 0 & 1 & n.s. \\
\hline & & - & 12 & 53 & \\
\hline HRAS & Hepatocyte nuclear factor 1 -alpha & + & 0 & 1 & n.s. \\
\hline & & - & 12 & 37 & \\
\hline IDHI & Isocitrate dehydrogenase [NADP] cytoplasmic & + & 0 & 3 & n.s. \\
\hline & & - & 12 & 35 & \\
\hline$J A K 2$ & Janus kinase 2 & + & 0 & 2 & n.s. \\
\hline & & - & 12 & 36 & \\
\hline$J A K 3$ & Janus kinase 3 & + & 0 & 2 & n.s. \\
\hline & & - & 12 & 36 & \\
\hline$K D R$ & Kinase Insert Domain Receptor & + & 0 & 3 & n.s. \\
\hline & & - & 12 & 35 & \\
\hline KIT & Mast/stem cell growth factor receptor Kit & + & 0 & 5 & n.s. \\
\hline & & - & 12 & 36 & \\
\hline KRAS & GTPase Kras & + & 2 & 89 & 0.04 \\
\hline & & - & 10 & 123 & \\
\hline MET & Hepatocyte growth factor receptor & + & 0 & 1 & n.s. \\
\hline & & - & 12 & 37 & \\
\hline
\end{tabular}


Table II. Continued

\begin{tabular}{|c|c|c|c|c|c|}
\hline Gene & Encoded protein & Mutation & $\mathrm{UC}-\mathrm{Ca}, \mathrm{n}$ & TCGA nature $2012, \mathrm{n}$ & $p$-Value* \\
\hline \multirow[t]{2}{*}{$M L H 1$} & DNA mismatch repair protein Mlh1 & + & 0 & 4 & n.s. \\
\hline & & - & 12 & 116 & \\
\hline \multirow{2}{*}{$M P L$} & MPL proto-oncogene, thrombopoietin receptor & + & 0 & 1 & n.s. \\
\hline & & - & 12 & 53 & \\
\hline \multirow[t]{2}{*}{$N M P 1$} & Nucleophosmin & + & 0 & 1 & n.s. \\
\hline & & - & 12 & 53 & \\
\hline \multirow[t]{2}{*}{ NRAS } & Transforming protein N-Ras & + & 0 & 12 & n.s. \\
\hline & & - & 12 & 108 & \\
\hline \multirow[t]{2}{*}{ PDGFRA } & Platelet-derived growth factor receptor alpha & + & 0 & 11 & n.s. \\
\hline & & - & 12 & 201 & \\
\hline \multirow[t]{3}{*}{ PIK $3 C A$} & Phosphatidylinositol 4,5-bisphosphate & + & 1 & 43 & n.s. \\
\hline & 3-kinase catalytic subunit alpha isoform & & & & \\
\hline & & - & 11 & 169 & \\
\hline \multirow[t]{2}{*}{ PTEN } & Phosphatase and tensin homolog & + & 0 & 3 & n.s. \\
\hline & & - & 12 & 35 & \\
\hline \multirow[t]{2}{*}{ PTPN11 } & Protein tyrosine phosphatase, non-receptor type 11 & + & 0 & 2 & n.s. \\
\hline & & - & 12 & 52 & \\
\hline \multirow[t]{2}{*}{$R B 1$} & $\mathrm{RB}$ transcriptional corepressor 1 & + & 0 & 1 & n.s. \\
\hline & & - & 12 & 37 & \\
\hline \multirow[t]{2}{*}{ RET } & Ret proto-oncogene & + & 0 & 2 & n.s. \\
\hline & & - & 12 & 36 & \\
\hline \multirow[t]{2}{*}{ SMAD4 } & Mothers against decapentaplegic homolog 4 & + & 2 & 24 & n.s. \\
\hline & & - & 10 & 188 & \\
\hline \multirow[t]{2}{*}{ SMARCB1 } & $\begin{array}{l}\text { SWI/SNF-related matrix-associated actin-dependent } \\
\text { regulator of chromatin subfamily B member } 1\end{array}$ & + & 0 & 3 & n.s. \\
\hline & & - & 12 & 117 & \\
\hline \multirow[t]{2}{*}{$S M O$} & Smoothened homolog & + & 0 & 1 & n.s. \\
\hline & & - & 12 & 53 & \\
\hline \multirow[t]{2}{*}{$S R C$} & Proto-oncogene tyrosine-protein kinase Src & + & 0 & 0 & n.s. \\
\hline & & - & 12 & 38 & \\
\hline \multirow[t]{2}{*}{ STK11 } & Serine/threonine-protein kinase STK11 & + & 0 & 0 & n.s. \\
\hline & & - & 12 & 120 & \\
\hline \multirow[t]{2}{*}{ TP53 } & Tumor protein P53 & + & 7 & 111 & n.s. \\
\hline & & - & 5 & 101 & \\
\hline \multirow[t]{2}{*}{$V H L$} & Von Hippel-Lindau disease tumor suppressor & + & 0 & 1 & n.s. \\
\hline & & - & 12 & 53 & \\
\hline
\end{tabular}

n.s.: Non-significant. *Fisher's test.

Kanazawa et al. reported higher concentrations of serum bFGF in patients with inflammatory bowel disease with a positive correlation to disease activity. They also confirmed the overexpression of bFGF in the epithelium of patients with colitis (23). Yamagata et al. reported the variability of concentration of bFGF in a single patient with colitic cancer and showed a higher bFGF-positive cell count in stenotic sites than that in non-stenotic sites (25). These reports imply that bFGF and its pathway play key roles in activated inflammation induced by immune dysfunction. Our study supports this speculation. We determined that FGFR2 mutation during UC carcinogenesis was already present in non-dysplastic mucosa. This alteration affects mucosal healing and degeneration and induces further inflammation and, as a result, higher levels of bFGF are recorded. As far as we know, this is the first report showing FGFR2 mutation in UC.

We also revealed that $C D H 1$ mutation occurred not only in the dysplastic epithelium but also in non-dysplastic mucosa in patients with colitic cancer. $C D H 1$ encodes E-cadherin, a glycoprotein that mediates intercellular connections by way of the zonula adherens. The alteration of CDH1 contributes to epithelial-mesenchymal transition, the biological phenomenon allowing epithelial cells to transition into fibroblastic cells with an ability to migrate and invade into the extracellular matrix $(26,27)$. 
Because this molecule is responsible for adherens junctions between epithelial cells, it is implicated in tumor progression in carcinogenesis $(28,29)$. A meta-analysis revealed that the polymorphism in CHD1 rs9929218 was associated with CRC (30). Moreover, the loss of $C D H 1$ expression was associated with infiltrative tumor growth and lymph node metastasis (31). These results suggested that the loss of $\mathrm{CDH} 1$ is a core factor for sporadic CRC progression.

In contrast, a study by Sommeren et al. revealed this to be a core molecule in pathogenesis of UC (12). Another study revealed a higher hypermethylation rate of the $\mathrm{CDH}$ promoter region in UC (32); this was positively associated with the severity of inflammation, age, and Mayo Endoscopic Scores (33). We consider that severe and longstanding inflammation in colorectal mucosa in UC causes hypermethylation of $C D H 1$, which in turn confers invasive potential on epithelial cells. These reports suggest a novel implication concerning the progression of UC; however, several facts had not been clarified.

Firstly, in the previous study about the relationship of CDH1 and colitis, the alteration was assessed by hypermethylation in the promoter region not by mutational analysis. Secondly, the previous report described the association only among the characteristics of colitis and CHD1 and did not comment on colitic carcinogenesis.

We consider that our study complements these previous findings. We examined the mutational rate of $\mathrm{CDH} 1$ in colitic cancer and showed that it did not differ from that of sporadic CRC. Moreover, our case with $C D H 1$ mutation in colitic cancer cells also showed mutation in non-neoplastic mucosa. Taking our results together with those of previous studies, we note that the mutational change in $C H D I$ had already occurred in non-neoplastic mucosa in UC. In contrast, as described in the previous report, during sporadic colorectal carcinogenesis, the adenoma did not exhibit mutation, whereas in our study, we found colitic cancer to have a similar mutation rate to sporadic CRC. These results suggest that $C D H 1$ mutation occurs while the adenoma progresses to carcinogenesis in sporadic CRC. This leads to the conclusion that $C D H 1$ mutation would appear to occur at a much earlier stage during carcinogenesis in colitic cancer than it does in sporadic CRC. The early acquisition of invasive potential conferred by $C D H 1$ mutation explains why colitic cancer is morphologically different from sporadic $\mathrm{CRC}$, invading into deeper layers when the tumor size is still relatively small.

The severity of inflammation of UC mucosa a known risk factor for colitic cancer, and $\mathrm{CDH} 1$ is reported as a predictor for the grade of inflammation $(11,12,34)$. Therefore, we consider that $\mathrm{CDH} 1$ mutation might be a risk factor for $\mathrm{UC}$ carcinogenesis, and this may extend to a therapeutic strategy for colitic cancer. An in vivo study by Inoue et al. gives indications of future developments of this hypothesis (35).
They artificially developed a chronic colitis model by administering 1,2-dimethylhydrazine and 3\% dextran sulfate sodium and examined tumorigenesis in mice sacrificed on the 28th day after administration. They observed fewer tumor nodules in mice that had been administered with Retodolac, compared with those without it. R-etodolac is known to up-regulate $C D H 1$. This result suggests that the induction of $\mathrm{CDH} 1$ potentially suppresses colitic cancer and implies that the induction of $C H D 1$ would be a possible key to the prevention or suppression of colitic cancer.

\section{Conclusion}

Colitic cancer presented a lower mutational rate of KRAS and $A P C$ than did sporadic cancer, in line with previous reports. We also showed that the mutation of FGFR2 had already occurred in non-dysplastic mucosa, which may affect mucosal healing and induce immune dysfunction. Moreover, the mutational rate of $C H D 1$, a key molecule in UC carcinogensis, was similar to that of $K R A S$ and $A P C$ in UC carcinogenesis, and occurs at an earlier stage than it does in sporadic CRC.

\section{Acknowledgements}

This research was supported by the Project for Cancer Research And Therapeutic Evolution (P-CREATE) from the Japan Agency for Medical Research and development, AMED.

\section{References}

1 Kinzler KW and Vogelstein B: Lessons from hereditary colorectal cancer. Cell 87(2): 159-170, 1996.

2 Vogelstein B, Fearon ER, Kern SE, Hamilton SR, Preisinger AC, Nakamura $\mathrm{Y}$ and White R: Allelotype of colorectal carcinomas. Science 244(4901): 207-211, 1989.

3 Vogelstein B, Fearon ER, Hamilton SR, Kern SE, Preisinger AC, Leppert M, Nakamura Y, White R, Smits AM and Bos JL: Genetic alterations during colorectal-tumor development. N Engl J Med 319(9): 525-532, 1988.

4 Nassif NT, Lobo GP, Wu X, Henderson CJ, Morrison CD, Eng $\mathrm{C}$, Jalaludin B and Segelov E: Pten mutations are common in sporadic microsatellite stable colorectal cancer. Oncogene 23(2): 617-628, 2004.

5 Powell SM, Zilz N, Beazer-Barclay Y, Bryan TM, Hamilton SR, Thibodeau SN, Vogelstein B and Kinzler KW: Apc mutations occur early during colorectal tumorigenesis. Nature 359(6392): 235-237, 1992.

6 Tanaka T, Watanabe T, Kazama Y, Tanaka J, Kanazawa T, Kazama S and Nagawa H: Loss of SMAD4 protein expression and $18 \mathrm{qLOH}$ as molecular markers indicating lymph node metastasis in colorectal cancer - a study matched for tumor depth and pathology. J Surg Oncol 97(1): 69-73, 2008.

7 Tanaka T, Watanabe T, Kazama Y, Tanaka J, Kanazawa T, Kazama $\mathrm{S}$ and Nagawa H: Chromosome 18q deletion and SMAD4 protein inactivation correlate with liver metastasis: A study matched for T- and N- classification. Br J Cancer 95(11): 1562-1567, 2006. 
8 Tanaka T, Watanabe T, Kitayama J, Kanazawa T, Kazama Y, Tanaka J, Kazama S and Nagawa H: Chromosome 18q deletion as a novel molecular predictor for colorectal cancer with simultaneous hepatic metastasis. Diagn Mol Pathol 18(4): 219225, 2009 .

9 Ullman TA and Itzkowitz SH: Intestinal inflammation and cancer. Gastroenterology 140(6): 1807-1816, 2011.

10 Strober W, Fuss I and Mannon P: The fundamental basis of inflammatory bowel disease. J Clin Invest 117(3): 514-521, 2007.

11 Thompson AI and Lees CW: Genetics of ulcerative colitis. Inflamm Bowel Dis 17(3): 831-848, 2011.

12 van Sommeren S, Visschedijk MC, Festen EA, de Jong DJ, Ponsioen CY, Wijmenga C and Weersma RK: HNF4alpha and Cdh1 are associated with ulcerative colitis in a Dutch cohort. Inflamm Bowel Dis 17(8): 1714-1718, 2011.

13 Yaeger R, Shah MA, Miller VA, Kelsen JR, Wang K, Heins ZJ, Ross JS, He Y, Sanford E, Yantiss RK, Balasubramanian S, Stephens PJ, Schultz N, Oren M, Tang L and Kelsen D: Genomic alterations observed in colitis-associated cancers are distinct from those found in sporadic colorectal cancers and vary by type of inflammatory bowel disease. Gastroenterology 151(2): 278-287, 2016.

14 Eaden JA, Abrams KR and Mayberry JF: The risk of colorectal cancer in ulcerative colitis: A meta-analysis. Gut 48(4): 526-535, 2001.

15 Jess T, Rungoe C and Peyrin-Biroulet L: Risk of colorectal cancer in patients with ulcerative colitis: A meta-analysis of population-based cohort studies. Clin Gastroenterol Hepatol 10(6): 639-645, 2012.

16 Hata K, Watanabe T, Kazama S, Suzuki K, Shinozaki M, Yokoyama T, Matsuda K, Muto T and Nagawa H: Earlier surveillance colonoscopy programme improves survival in patients with ulcerative colitis associated colorectal cancer: Results of a 23-year surveillance programme in the Japanese population. Br J Cancer 89(7): 1232-1236, 2003.

17 Hata K, Watanabe T, Shinozaki M, Kojima T and Nagawa H: To dye or not to dye? That is beyond question! Optimising surveillance colonoscopy is indispensable for detecting dysplasia in ulcerative colitis. Gut 53(11): 1722, 2004.

18 Hata $\mathrm{K}$, Watanabe $\mathrm{T}$, Motoi $\mathrm{T}$ and Nagawa $\mathrm{H}$ : Pitfalls of pit pattern diagnosis in ulcerative colitis-associated dysplasia. Gastroenterology 126(1): 374-376, 2004.

19 Robles AI, Traverso G, Zhang M, Roberts NJ, Khan MA, Joseph C, Lauwers GY, Selaru FM, Popoli M, Pittman ME, Ke X, Hruban RH, Meltzer SJ, Kinzler KW, Vogelstein B, Harris CC and Papadopoulos N: Whole-exome sequencing analyses of inflammatory bowel disease-associated colorectal cancers. Gastroenterology 150(4): 931-943, 2016.

20 Andreyev HJ, Norman AR, Cunningham D, Oates J, Dix BR, Iacopetta BJ, Young J, Walsh T, Ward R, Hawkins N, Beranek M, Jandik P, Benamouzig R, Jullian E, Laurent-Puig P, Olschwang S, Muller O, Hoffmann I, Rabes HM, Zietz C, Troungos C, Valavanis C, Yuen ST, Ho JW, Croke CT, O’Donoghue DP, Giaretti W, Rapallo A, Russo A, Bazan V, Tanaka M, Omura K, Azuma T, Ohkusa T, Fujimori T, Ono Y, Pauly M, Faber C, Glaesener R, de Goeij AF, Arends JW, Andersen SN, Lovig T, Breivik J, Gaudernack G, Clausen OP, De Angelis PD, Meling GI, Rognum TO, Smith R, Goh HS, Font A, Rosell R, Sun XF, Zhang H, Benhattar J, Losi L, Lee
JQ, Wang ST, Clarke PA, Bell S, Quirke P, Bubb VJ, Piris J, Cruickshank NR, Morton D, Fox JC, Al-Mulla F, Lees N, Hall CN, Snary D, Wilkinson K, Dillon D, Costa J, Pricolo VE, Finkelstein SD, Thebo JS, Senagore AJ, Halter SA, Wadler S, Malik S, Krtolica $\mathrm{K}$ and Urosevic N: Kirsten ras mutations in patients with colorectal cancer: The 'RASCAL II' study. Br J Cancer 85(5): 692-696, 2001.

21 Rapozo DC, Grinmann AB, Carvalho AT, de Souza HS, SoaresLima SC, de Almeida Simao T, de Paiva D, Abby F, Albano RM and Pinto LF: Analysis of mutations in TP53, APC, KRAS, and $D C C$ genes in the non-dysplastic mucosa of patients with inflammatory bowel disease. Int J Colorectal Dis 24(10): 1141$1148,2009$.

22 Odze RD, Brown CA, Hartmann CJ, Noffsinger AE and Fogt F: Genetic alterations in chronic ulcerative colitis-associated adenoma-like dalms are similar to non-colitic sporadic adenomas. Am J Surg Pathol 24(9): 1209-1216, 2000.

23 Kanazawa S, Tsunoda T, Onuma E, Majima T, Kagiyama M and Kikuchi K: Vegf, basic-FGF, and TGF-beta in crohn's disease and ulcerative colitis: A novel mechanism of chronic intestinal inflammation. Am J Gastroenterol 96(3): 822-828, 2001.

24 Kadono T, Kikuchi K, Kubo M, Fujimoto M and Tamaki K: Serum concentrations of basic fibroblast growth factor in collagen diseases. J Am Acad Dermatol 35(3 Pt 1): 392-397, 1996.

25 Yamagata M, Mikami T, Tsuruta T, Yokoyama K, Sada M, Kobayashi K, Katsumata T, Koizumi W, Saigenji K and Okayasu I: Submucosal fibrosis and basic-fibroblast growth factorpositive neutrophils correlate with colonic stenosis in cases of ulcerative colitis. Digestion 84(1): 12-21, 2011.

26 Kalluri R and Neilson EG: Epithelial-mesenchymal transition and its implications for fibrosis. J Clin Invest 112(12): 17761784, 2003.

27 Auersperg N, Pan J, Grove BD, Peterson T, Fisher J, MainesBandiera S, Somasiri A and Roskelley CD: E-Cadherin induces mesenchymal-to-epithelial transition in human ovarian surface epithelium. Proc Natl Acad Sci USA 96(11): 62496254, 1999.

28 Tsanou E, Peschos D, Batistatou A, Charalabopoulos A and Charalabopoulos K: The E-cadherin adhesion molecule and colorectal cancer. A global literature approach. Anticancer Res 28(6A): 3815-3826, 2008.

29 Chen X, Wang Y, Xia H, Wang Q, Jiang X, Lin Z, Ma Y, Yang $\mathrm{Y}$ and $\mathrm{Hu} \mathrm{M}$ : Loss of E-cadherin promotes the growth, invasion and drug resistance of colorectal cancer cells and is associated with liver metastasis. Mol Biol Rep 39(6): 6707-6714, 2012.

30 Han P, Liu G, Lu X, Cao M, Yan Y, Zou J, Li X and Wang G: Cdh1 rs9929218 variant at $16 \mathrm{q} 22.1$ contributes to colorectal cancer susceptibility. Oncotarget 7(30): 47278-47286, 2016.

$31 \mathrm{Kim}$ SA, Inamura K, Yamauchi M, Nishihara R, Mima K, Sukawa Y, Li T, Yasunari M, Morikawa T, Fitzgerald KC, Fuchs CS, Wu K, Chan AT, Zhang X, Ogino S and Qian ZR: Loss of CDH1 (E-cadherin) expression is associated with infiltrative tumour growth and lymph node metastasis. Br J Cancer 114(2): 199-206, 2016.

32 Prager M, Buettner $\mathrm{J}$ and Buening $\mathrm{C}$ : Genes involved in the regulation of intestinal permeability and their role in ulcerative colitis. J Dig Dis 16(12): 713-722, 2015.

33 Tahara T, Shibata T, Okubo M, Ishizuka T, Nakamura M, Nagasaka M, Nakagawa Y, Ohmiya N, Arisawa T and Hirata I: 
DNA methylation status of epithelial-mesenchymal transition (EMT)-related genes is associated with severe clinical phenotypes in ulcerative colitis (UC). PLoS One 9(10): e107947, 2014.

34 Saito S, Kato J, Hiraoka S, Horii J, Suzuki H, Higashi R, Kaji E, Kondo Y and Yamamoto K: DNA methylation of colon mucosa in ulcerative colitis patients: Correlation with inflammatory status. Inflamm Bowel Dis 17(9): 1955-1965, 2011.
35 Inoue T, Murano M, Yoda Y, Kuramoto T, Kakimoto K, Ishida K, Kawakami K, Abe Y, Morita E, Murano N, Tokioka S, Maemura $\mathrm{K}$, Umegaki $\mathrm{E}$ and Higuchi K: R-etodolac induces E-cadherin and suppresses colitis-related mouse colon tumorigenesis. Oncol Rep 24(6): 1487-1492, 2010.

Received July 15, 2017

Revised August 3, 2017

Accepted August 4, 2017 